\title{
Duloxetine in panic disorder with somatic gastric pain
}

This article was published in the following Dove Press journal:

Neuropsychiatric Disease and Treatment

20 November 2013

Number of times this article has been viewed

\author{
Matteo Preve' \\ Cristiana Nisita' \\ Massimo Bellini² \\ Liliana Dell'Osso' \\ 'Department of Psychiatry, \\ Neurobiology, Pharmacology and \\ Biotechnology, ${ }^{2}$ Department of \\ Gastroenterology, Gastrointestinal \\ Unit, University of Pisa, Pisa, Italy
}

Correspondence: Matteo Preve Department of Psychiatry, Neurobiology, Pharmacology and Biotechnology, University of Pisa, via Roma 67, 56100 Pisa, Italy

Fax +390509 93267

Email m_preve@yahoo.com

\begin{abstract}
Panic disorder is the most common type of anxiety disorder, and its most common expression is panic attacks characterized with sudden attacks of anxiety with numerous symptoms, including palpitations, tachycardia, tachypnea, nausea, and vertigo: ie, cardiovascular, gastroenterologic, respiratory, and neuro-otologic symptoms. In clinical practice, panic disorder manifests with isolated gastroenteric or cardiovascular symptoms, requiring additional clinical visits after psychiatric intervention. The first-line treatment for anxiety disorders, and in particular for panic disorder, is the selective serotonin reuptake inhibitors. However, these drugs can have adverse effects, including sexual dysfunction, increased bodyweight, and abnormal bleeding, that may be problematic for some patients. Here we report the case of a 29-year-old Caucasian woman affected by panic disorder with agoraphobia who was referred to our clinic for recurrent gastroenteric panic symptoms. The patient reported improvement in her anxiety symptoms and panic attacks while on a selective serotonin reuptake inhibitor, but not in her gastric somatic problems, so the decision was taken to start her on duloxetine, a serotonin-norepinephrine reuptake inhibitor. After 6 months of treatment, the patient achieved complete remission of her gastric and panic-related symptoms, and was able to stop triple gastric therapy. Other authors have hypothesized and confirmed that duloxetine has greater initial noradrenergic effects than venlafaxine and is effective in patients with panic disorder. This case report underscores the possibility of tailoring therapeutic strategies for the gastroenteric expression of panic disorder.
\end{abstract}

Keywords: anxiety disorder, panic attacks, palpitations, tachycardia, tachypnea, nausea, vertigo

\section{Introduction}

Anxiety disorders are the most common type of psychiatric disorder, with a mean incidence of $18.1 \%$ and a lifetime prevalence of $28.8 \% .{ }^{1}$ Panic attacks are the most common type of anxiety disorder, with lifetime prevalence estimates of $22.7 \%$ for isolated (ie, without panic disorder) panic attacks without agoraphobia, $0.8 \%$ for isolated panic attacks with agoraphobia, 3.7\% for panic disorder without agoraphobia, and $1.1 \%$ for panic disorder with agoraphobia. All four subgroups have significant comorbidity with other lifetime DSM-IV (Diagnostic and Statistical Manual of Mental Disorders, 4th Edition) disorders, with the highest rates of comorbidity in panic disorder with agoraphobia and the lowest in isolated panic attacks. ${ }^{2}$ Panic attacks are characterized by sudden attacks of anxiety with numerous somatic symptoms, including palpitations, tachycardia, tachypnea, nausea, and vertigo (ie, cardiovascular, gastroenterologic, respiratory, and neuro-otologic symptoms). In clinical practice, panic disorder may also be observed with isolated gastroenteric or cardiovascular 
symptoms requiring further clinical consultations following psychiatric intervention. Selective serotonin reuptake inhibitors are the preferred treatment for anxiety disorders, and for panic disorder in particular. However, these drugs can have adverse effects, including sexual dysfunction, ${ }^{3}$ increased bodyweight, ${ }^{4}$ and abnormal bleeding, ${ }^{5}$ so their use may be problematic in some patients.

\section{Case report}

GV, a 29-year-old Caucasian woman suffering from panic disorder with agoraphobia, was referred to our clinic for recurrent gastroenteric panic symptoms. She had a negative family history for mental illness and had no past history of substance use/abuse. The patient's psychiatric history dated back to 8 years previously when, at the age of 21 years, she presented with somatic panic symptoms, ie, tachycardia, chest tightness, heartburn, and panic attacks. On her first outpatient visit to the gastroenterology clinic at the age of 26 years, she presented with recurrent heartburn, but tested negative for hiatal hernia, Helicobacter pylori, and esophagogastric reflux. At that time, she was also experiencing isolated panic attacks characterized by palpitations (tachycardia), chest tightness, somatopsychic depersonalization, fear of dying, anticipatory anxiety, harm avoidance, and a fear of being alone. She was not given any psychopharmacologic treatment but was treated with triple gastric therapy comprising a proton pump inhibitor (esomeprazole), antacids (alginic acid and sodium bicarbonate), and an antidopaminergic gastrointestinal prokinetic agent (clebopride).

At the first outpatient visit, the patient presented primarily with somatic symptoms, including heartburn, chest tightness and pain, somatopsychic depersonalization, tachycardia, and fear of dying and anxiety in the context of asthenia and anergia. We assessed her symptomatology using the Structured Clinical Interview for Panic-Agoraphobic Spectrum lifetime version, ${ }^{6}$ and the score was 85 at the first visit. We initially prescribed citalopram $20 \mathrm{mg} /$ day, but the patient reported sexual dysfunction (reduction/loss of libido and difficulty achieving orgasm), cognitive impairment, and fatigue. The patient reported improvement in her anxiety symptoms and panic attacks on a selective serotonin reuptake inhibitor, but not in her troublesome gastric somatic symptoms. We therefore decided to gradually reduce the dose of citalopram and introduced escitalopram $7 \mathrm{mg} /$ day, but the patient continued to report loss of libido with no change in her gastric symptoms. We then prescribed duloxetine $30 \mathrm{mg} /$ day, which was subsequently increased to $60 \mathrm{mg} /$ day, with slow withdrawal of escitalopram. After 6 months of treatment, the patient showed complete remission of her gastric and panicrelated symptoms, and all three gastric treatments were able to be discontinued.

\section{Discussion}

This case report underscores the possibility of tailoring therapeutic strategies for the gastroenteric expression of panic disorder. Selective serotonin reuptake inhibitors remain the first-line treatment for panic disorder, and paroxetine is the gold standard among these psychopharmacologic medications. ${ }^{7,8}$ However, these drugs can have adverse effects, including sexual dysfunction, increased bodyweight, and abnormal bleeding, leading to problems with continuation of therapy. The opportunity to have another therapeutic option with fewer adverse effects is important and helpful. Other researchers, such as Simon et al, have hypothesized and confirmed that duloxetine, a serotonin-norepinephrine reuptake inhibitor with greater initial noradrenergic effects than venlafaxine, has broad efficacy in individuals with panic disorder. ${ }^{9,10}$ Our interest in duloxetine lies in the possibility of treatment for panic disorder with the added benefit of resolution of gastric symptoms. As other researchers have pointed out, duloxetine acts on the neuropathic pain caused by fibromyalgia, neuropathic diabetes, ${ }^{11-13}$ and irritable bowel syndrome, ${ }^{14}$ and has fewer sexual and cognitive adverse effects. Moreover, descending serotonin and norepinephrine pathways have been suggested to be modulators of pain perception, ${ }^{15}$ and duloxetine has been shown to have an analgesic effect on painful physical symptoms that are partially independent of the improvement in major depressive disorder. ${ }^{15,16}$

Our patient presented with panic disorder and a combination of gastroenteric symptoms in the context of asthenia, anergia, and severe adverse effects due to treatment with a selective serotonin reuptake inhibitor, suggesting the possibility that a serotonin-norepinephrine reuptake inhibitor such as duloxetine may be of some value in patients presenting with such symptoms in a psychopathologic context. Obviously, further research is warranted to replicate our clinical observations and, in general terms, controlled studies are needed to confirm the efficacy of this treatment.

\section{Disclosure}

The authors report no conflicts of interest in this work. 


\section{References}

1. Kessler RC, Chiu WT, Demler O, Merikangas KR, Walters EE. Prevalence, severity, and comorbidity of 12-month DSM-IV disorders in the National Comorbidity Survey Replication. Arch Gen Psychiatry. 2005;62(6):617-627.

2. Kessler RC, Chiu WT, Jin R, Ruscio AM, Shear K, Walters EE. The epidemiology of panic attacks, panic disorder, and agoraphobia in the National Comorbidity Survey Replication. Arch Gen Psychiatry. 2006;63(4):415-424.

3. Serretti A, Chiesa A. Sexual side effects of pharmacological treatment of psychiatric diseases. Clin Pharmacol Ther. 2011;89(1):142-147.

4. Serretti A, Mandelli L. Antidepressant and body weight: a comprehensive review and meta-analysis. J Clin Psychiatry. 2010;71(10):1259-1272.

5. Andrade C, Sandarsh S, Chethan KB, Nagesh KS. Serotonin reuptake inhibitor antidepressant and abnormal bleeding: a review for clinicians and a reconsideration of mechanism. J Clin Psychiatry. 2010;71(12):1565-1575.

6. Shear MK, Frank E, Rucci P, et al. Panic-agoraphobic spectrum: reliability and validity of assessment instruments. J Psychiatr Res. 2001;35(1):59-66.

7. Bakker A, van Balkom AJ, Spinhoven P. SSRIs vs TCAs in the treatment of panic disorder: a meta-analysis. Acta Psychiatr Scand. 2002;106(3): $163-167$.

8. Sheehan DV, Harnett-Sheehan K. The role of SSRIs in panic disorder. J Clin Psychiatry. 1996;57 Suppl 10:51-58.

9. Serretti A, Chiesa A, Calati R, Perna G, Bellodi L, De Ronchi D. Novel antidepressants and panic disorder: evidence beyond current guidelines. Neuropsychobiology. 2011;63(1):1-7.
10. Simon NM, Kaufman RE, Hoge EA, et al. Open-label support for duloxetine for the treatment of panic disorder. CNS Neurosci Ther. 2009;15(1):19-23.

11. Chouinard G. The search for new off-label indications for antidepressant, antianxiety, antipsychotic and anticonvulsant drugs. J Psychiatry Neurosci. 2006;31(3):168-176.

12. Arnold LM, Wang F, Ahl J, Gaynor PJ, Wohlreich MM. Improvement in multiple dimensions of fatigue in patients with fibromyalgia treated with duloxetine: secondary analysis of a randomized, placebo-controlled trial. Arthritis Res Ther. 2011;13(3):R86.

13. Wright A, Luedtke KE, Vandenberg C. Duloxetine in the treatment of chronic pain due to fibromyalgia and diabetic neuropathy. J Pain Res. 2010;4:1-10.

14. Brennan BP, Fogarty KV, Roberts JL, Reynolds KA, Pope HG Jr, Hudson JI. Duloxetine in the treatment of irritable bowel syndrome: an open-label pilot study. Hum Psychopharmacol. 2009;24(5): 423-428.

15. Perahia DG, Pritchett YL, Desaiah D, Raskin J. Efficacy of duloxetine in painful symptoms: an analgesic or antidepressant effect? Int Clin Psychopharmacol. 2006;21(6):311-317.

16. Ball SG, Desaiah D, Spann ME, et al. Efficacy of duloxetine on painful physical symptoms in major depressive disorder for patients with clinically significant painful physical symptoms at baseline: a metaanalysis of 11 double-blind, placebo-controlled clinical trials. Prim Care Companion CNS Disord. 2011;13(6).
Neuropsychiatric Disease and Treatment

\section{Publish your work in this journal}

Neuropsychiatric Disease and Treatment is an international, peerreviewed journal of clinical therapeutics and pharmacology focusing on concise rapid reporting of clinical or pre-clinical studies on a range of neuropsychiatric and neurological disorders. This journal is indexed on PubMed Central, the 'PsycINFO' database and CAS.

\section{Dovepress}

The manuscript management system is completely online and includes a very quick and fair peer-review system, which is all easy to use. Visit http://www.dovepress.com/testimonials.php to read real quotes from published authors. 